Purdue University Purdue e-Pubs

1992

\title{
Using Shot Peening to Multiply the Life of Compressor Components
}

J. S. Eckersley

Metal Improvement Company

B. Ferrelli

Metal Improvement Company

Follow this and additional works at: https://docs.lib.purdue.edu/icec

Eckersley, J. S. and Ferrelli, B., "Using Shot Peening to Multiply the Life of Compressor Components" (1992). International Compressor Engineering Conference. Paper 885.

https://docs.lib.purdue.edu/icec/885

This document has been made available through Purdue e-Pubs, a service of the Purdue University Libraries. Please contact epubs@purdue.edu for additional information.

Complete proceedings may be acquired in print and on CD-ROM directly from the Ray W. Herrick Laboratories at https://engineering.purdue.edu/ Herrick/Events/orderlit.html 


\title{
USING SHOT PEENING TO MULTIPLY THE LIFE OF COMPRESSOR COMPONENTS
}

\author{
John \$. Eekersley \\ Buzz Ferrelli \\ Metal Improvement Company \\ Bloomfield, Connecticut
}

\section{ABSTRACT}

Fatigue 1 ife increases, by orders of magnitude, can be expected on compressor components treated by shot Peening - a controlied process that involves the bombardment of the metal component by millions of spherical particles of steel, glass or ceramic. Shot Peening is being applied to crankshafts and con-rods of huge reciprocating compressors and to the small valve reeds, on ly a few thousands of an inch thick, that are the heart of refrigeration and air conditioning sealed units. In what is perhaps the "ultimate" in design of axial and centrifugal compressors, the modern jet engine, Shot Peening is used on a 1 rotating parts, as well as many of the stationary ones, to prevent premature fatilures from metal fatigue, corrosion and fretting fatigue, and from stress corrosion cracking.

The paper reviews these and other applications for compressor engineers so that they will be able to increase the life and/or the loading on both new and existing designs, without increasing size or adding weight to criticai components. The controlling parameters of the shot Peening process are also discussed.

\section{HISTORICAL BACKGROUND.}

Shot Peening was first used, in a production application, to extend the Tife of the valve springs for the Buick and cadillac engines of the early 1930s (Ref. 1 ). The process was discovered accidentally and, although the benefits were soon recognized, it was several years before a mechanism was proposed and even longer before is was generally accepted. It was recognized, at the time, that fatigue cracks initiated under repeated tensile loads. John Almen postulated that shot peening produced the increases in fatigue $1 \mathrm{ife}$ from the introduction, of a high residual compressive stress, which remained just below the surface of the part (Fig. 1, Ref. 2).

\section{fIGURE 1. EXAMPLE OF RESIOUAL STRESS PROFILE CREATED bY SHOT PEENING.}

In most appljcations for shot peening, the benefit obtained is the direct result of the residual compressive stress produced. A typical prof i le of residual compressive stress as it changes with depth is shown. "Yit has four important
characteristics:

1) Ss - Surface stress - The stress measured at the surface.

2) CS max - Maximum Compressive Stress - The maximum value of the compressive stress induced, which normally is highest just below the surface.

3) $d-$ Depth - The depth of the comr pressive stress is the point at which the compressive stress crosses over the neutral axis and becomes tens ile.

4) T5 max - Maximum Tensile stress - The maximum value of the tens $i$ le stress induced. The of fsetting tensile stress in the core of the material balances the surface layer of compressive stress so that the part remains in equilibrium, Ts max must not be allowed to become large enough to create early internal faltures.

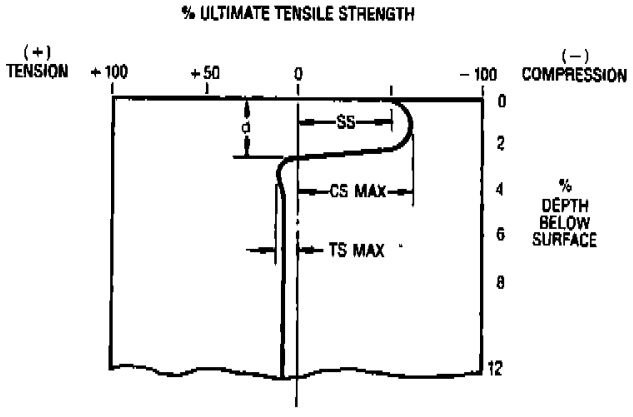


Any applied tensile loads, affirmed Almen, would have to overcome this residual compression before a crack could start. Furthermore; Almen claimed that many parts.(springs, for instance, from the coiling operation) had in them, from manufacturing, residual tensile stresses, that when added upon by the tensile loads, would further contribute to the part's early failure. Shot Peening, he said, reversed the surface residual stress from tension to compression, accounting for the very great improvements in fatigue life that are typical of the process. The academic community was almost totally opposed to John Almen's theories since, at the time, the presence of residual stresses in metals was not recognized in engineering calculations. The advent of Fracture Mechanics eventually vindicated. Almen's position. Today, we not only recognize residual (or self) stresses: we are able to measure them with a considerable degree of consistency, primarily by x-ray diffraction.

\section{Consideration of Residual Stresses}

If the part is dimenaionaliy correct, are residual stresses all that important, in a fatigue application? A very current case is an excellent iliustration. A group of engineers are developing a torsion bar for a space apolication (the exact nature is "classified"). They carefully ground the test torsion bars to produce the final profile and a smooth surface. The unpeened torsion bars, at the applied load level, averaged close to a milition eycles to failure and the stress anaiyst in the group figured from this information, that shot peening would about double the life of the bars, to two million cycles: sufficient for the application. To his surprise, the first (and only) shot Peened torsion bar that they tested ran for 166 mi1= ion cycles when the test was discontinued.

FIGURE 2. RESIDUAL STRESS IN 4340 STEEL (HRC 50) AFTER SURFACE GRINDING.

Graph shows the stress distribution Craph shous the stress disting techcreated - cy dfontionel, busive and niques - conventional, abusive and gentle. It is quite ovident that conventional grinding and abusive orinding can generate high magnigrind ing can or near the surface of the parts. course, dramaticaily affect fatigue resistance.

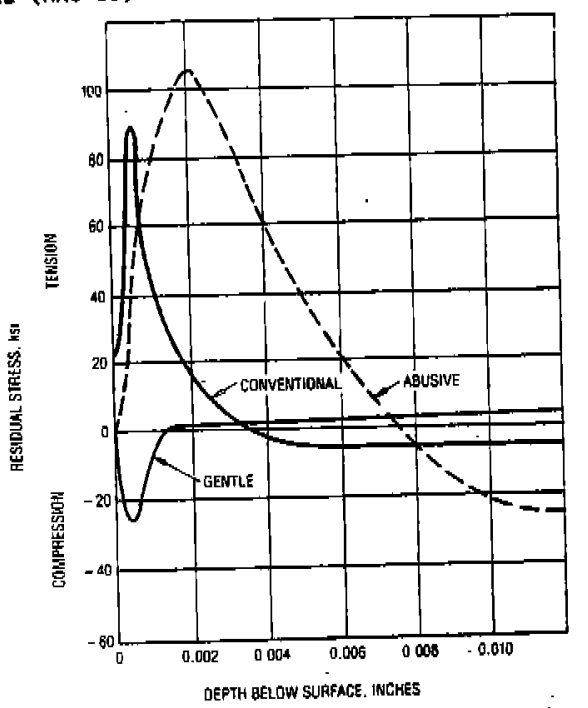

The stress analyst had based his calculations on the assumption that the unpeened torsion bars were in a "neutral" state of stress before any loads were applied. In reality, the grinding operation had introduced residual tensile stresses, which in extreme cases can actually exceed the yield strength of the metal (Fig. 2, Ref. 3). The failures at a million cycles were actually premature failures caused by the debiting effect of the grinding stresses. When the bars were 
Shot Peened, the surface residual stresses were reversed, from close to the yield strength in tension to close to the yield strength in compression or a delta, in this case, of over $300 \mathrm{kSI}$. The Shot Peening actually rajsed the endurance 1 imit of the torsion bars well over the stress level applied in the testing, contributing to virtually infinite 1 ife. Not all applications of Shot Peening are so dramatic but this is a good reminder that residual stresses, detrimental or beneficial, should not be ignored.

Realizing that the Purdue Conference is directed almost exclusive1y at engineers involved with small compressors for refrigeration and air conditioning, we thought it would bo useful to review, quite briefly, some of the applications of the shot Peening process in the very large or very different compressors that are found in other industries, since much can be learned from them. Then, we want to be more specific in discussing the benefits of shot Peening for valve reeds and rings since our unique success in this area has propelled Metal Improvement company to become one of the leading manufactures of these very critical components.

\section{SHOT PEENING FOR INDUSTRIAL AND AIRCRAFT COMPRESSORS}

\section{Reciprocating Compressors}

1. Crankshafts are most commonly peened in the fillets of the pins and mains to produce increases in fatigue strength of up to $30 x$. Crankshafts have also been peened in the oil holes and keyways (Fig. FIGURE 3. INCREASE IN FATIGUE STRENGTH OF SHOT PEENED CRANKSHAFTS.

The most highly stressed area of a crankshaft is the crank pin bearing fillot. The high stress point is the bottom side of the fillet when the pin is in the top dead center position during the firing cycle. It ys comon for cracks to in the top main bearing filiet, causing fat through the web of the crankshaft to the adjecent main tearing fillet, causing fatigue faflure. All sizes of crankshafts respond of i" to large slow' spegd shafts having Journal bearing dournal bearing. dianeters Experience has shown the process to be effective on forged sted 1 , cast steel, nodular iron, and austempered duct ile iron.
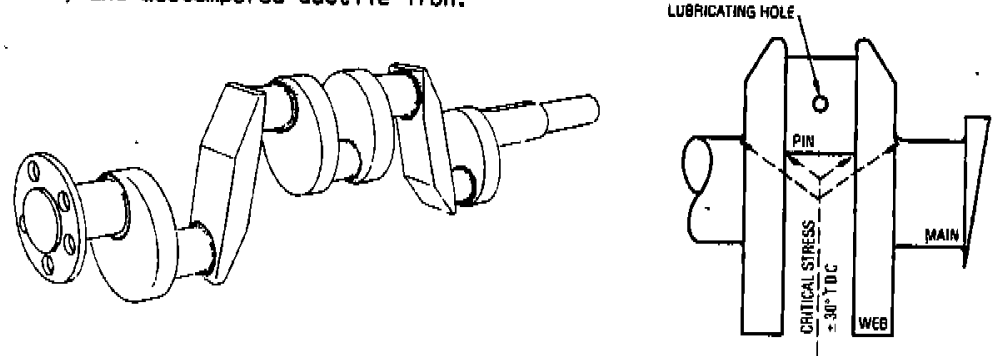

2. Connecting Rods are usually peened prior to machining, to prevent fatigue fajlures in the I-beam section but some large ones are also peened in the oil holes and in the fillets by the bolts. Fretting fatigue is prevented by peening the serrations between the rod and the cap, the bearing surfaces, and the bolt holes.

3. Connecting Rod Bolts are shot peened for axial fatigue in the shank to head fillet and for fretting fatigue in the shank itself. Sometimes, the thread roots are peened, which can impart to a cut thread almost the same fatigue strength as a rolied thread.

4. Tie-Rod Bolts are used in very large compressors to hold the assembly together or are used just around the cylinder heads. These bolts are peened for the same raasons as the connecting rod bolts described above.

5. Tail Rod cylinders are peened at the intersections of crossbores to prevent crack initiation.

6. Hyper cups are used to hold the seal around the push rods of Very high pressure (approaching 50,000 PSI) compressors. The shot Peening retards failures from bending and fretting fatigue.

7. Ring and Strip Valves are edge finished and peened for very high cycle fatigue. 
Impellers have been Shot Peened that range in size from less than 2 inches in diameter for a space application to 48 inches for process air.. Turbochargers fall under this classification and many are shot mal cracking at some locating serrations on the back face of aluminum impellers for locomotive diesel turbochargers. Of concern was the heat that might relieve the compressive stresses form shot Peening. However, peening solved the problem, using glass beads to avoid ferrous contamination of the aluminum.

Most of the smaller turbines employed in aircraft, sometimes for propulsion, but most often as auxiliary power units, air starters, etc., use shot Peened impellers, as do the engines for the Cruise Missile. Significant weight reductione are possible by including the benefits of shot Peening in the design calculations. Materials for impellers, incidentally, may be sand cast iron or aluminum, welded steel, forged aluminum or titanium; even investment cast superalloys: a11 respond wel1 to shot Peening.

\section{Axial Compressors}

Many are used in stationary applications (a good one is for making snow on the ski slopes), but most axial compressors are used in combination with a gas turbine to form a jet engine and provide oropulsion for planes, boats and trains, and some experimental trucks. Because of the extreme centrifugal, axial and vibrational forces acting on the rotating components, ali shafts, disks and blades are typically shot Peened against bonding and fretting fatigue. In fact, there are very few components of a high performance jet engine that are not peened, both during original manufacture and again at periodic overhaul intervals, and include less obvious components such as gears and fuel lines.

\section{Dianhragm Compressors}

Diaphragm compressors are quite uncommon and are used in applications where absolutely no contamination (from lubricating oils, for instance) of the compressed gas is permitted. The critical component is a large (up to 30 inches diameter by 0.030 inch thick) stainiess steel diaphragm that is clamped around the edges in the compressor head. Because the diaphragm moves up and down under hydraul1c pressure, cracks initiate just inside of the bolt hole ring. Typically, a chemical company, compressing Freon, used to replace these diaphragms every 16 hours of service. Peening the diaphragm with glass beads (on stainless steel) extended the service 1 ife to 6 months. The difficulty here is to peen the large but very thin diaphragm and still maintain flatness: exactly the same problem that is encountered in peening the small valve reeds with which you are all famrliar.

\section{COMPRESSOR VALVE COMPONENTS}

To quote D. N. Lal, Research Engineer at the Carrier Corporation: "The valve, suetion or discharge, is one of the most critical components of a compressor. A flapper valve is required to have high flexibility to allow unrestricted fluid passage through the ports for achieving high efficiency and capacity of the compressor, but at the same time it is also expected to have enough stiffness to return back in time to seal the ports completely. The motion subjects the valve to severe cyclic stresses and strains. To make the situation worse, most of the valves have irregular geometry as unavoidable design requirements. This increases the possibility of localized stress concentration and premature failure by fatigue" (Ref. 5). Fow would dispute Lal's statement but it leaves the designer of a compressor with having to make a serious compromise between the efficiency of the compressor and the life of the valve. The more the flapper reed flexes, the more passage of fluid it will permit but the shorter will be the number of flexures the flapper wil1 sustain before breaking. It is incumbent on the designer to seek a reed that will allow the maximum passage of fluid without breakage during the expected life of the compressor at, let's not forget, a cost that is within budget. 
The geometry of the reed is usually the first consideration and one over which the manufacturer of the reed has ittie control. Actual1y, the designers are much better served if they include the manufacturer at an oarly stage of the design. A manufacturer of reeds should not just be able to stamp out metal. shapes: he must thorough1y understand al1 the factors that influence the 1 ife expectancy of a valve. For instance, the diameter of a mounting hole or the width of a slot, within obvious 1 imits, may have ittele influence on the efficiency of a reed but they can create difficulties for the reed maker that will impact both on the 1 ife and the cost of a reed. The reed maker must have a complete knowledge of materials; stresses (applied and residual; beneficial and detrimental); how life is affected by edge geometry, surface conditions, heat and corrosion; and the influence of bending, torsion and impact loads. Because his speciality 1 s valves (and not compressors) the reed manufacturer can be of great value to the designer.

The ideal valve reed would open fully and close totally in zero time: and last forever. We certainly are not there yet but an ovolving technology, based on a more complete understanding of the many phenomena involved, is taking the best reed makers ever closer. We know that there are at least five areas that must be given attention: 1. Choice of materia1, 2. Stamped edges, 3. Removal of defects and detrimental stresses, 4. Edge rounding, 5. Depth and magnitude of beneficial stress. We will address each of these items individually but it must be remembered that al1 are very much interrelated. For instance, maximizing $\$ 5$, in theory would atlow the use of thinner steel (*1) so that the reed would flex more and faster but maintaining flatness could then become a difficulty that would compromise the reed's ability to close totally. Overcoming this difficulty is the province of a good reed maker and much has been done in this area. Fursuing al1 of the above items to the maximum of currant technology wi11 produce a reed closest to the ideal. The extent of this pursuit is governed by the cost considerations of the application and the degree- of efficiency that the designer wishes to obtain for the compressor. Designers need to be aware of the options avallable to them.

\section{Choice of Material}

There is much information published by the suppliers of valve steels and it is not our province to review it in detail. High car bon strip is the choice for thin reeds and is supplied and stamped in the pre-hardened condition. Nickel-alloyed steel is usually used for thicker valves and hardened after stamping. Stainless is preferred for applications where corrosion can be a problem (Fig. 4, Ref. 6), such as in the presence of air, water or steam, ditute organic acids and sulphurous fumos. A corrosive environment wil? always lower fatigue properties, even in stainless steels, but the effect can be largely over come by the introduction of high residual compressive
stresses.

\section{FIGURE 4, STRESS CORROSION CRACKING.}

Effect of shot peening with $40-80 \mathrm{~m}$ glass shot on the times to fallure to type 304 and 347 stainiess steels in a boiling 428 magnesium chioride solution.

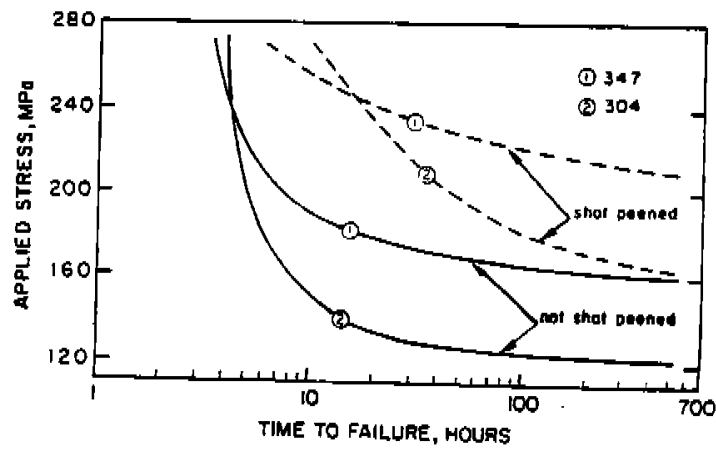


A fatigue failure'will always nucleate at the point of greatest stress concentration: sometimes at an inclusion in the steel, but in the case of valve reeds, almost always at a surface defect created by the stamping operation (Ref. 7). Al1 subsequent operations, i.e., edge rounding, removal of defects and introduction of beneficial stresses, are all performed primarily to remove or offset these surface defects from stamping. The technology of producing good reeds is totally tied to the technique of producing stamped edges that are as free from defects as possible. The importance of this will become more apparent as we look at the subsequent operations.

Removal of Defects and Detrimental Stresses

There are a variety of processes available to the reed maker to, essentially, wear away the stamped edges and smooth out the stress concentrating defects. A11 are very time-consuming (and cost raising) and have limitations, especially from reed geometry. For instance, rough edges of narrow slots and sma 11 holes are very difficult to smooth out without loosing dimensions on the more exposed edges. starting with stamped edges that are essentially free of defects is paramount here. Also, the stamping operation introduces residual tensile stresses at the edges of the reed. A good edge finishing process, such as STRESS-LITE, (Fig. 5, Ref. 8) will reverse these detrimental residual tensile stresses into beneficial compressive stresses but, again, starting with a near perfect stamping makes the stress reversal process not only more effective but, in some cases, even possible.

FIGURE 5. LCF OF SUCTION VALVE, IN THREE CONDITIONS.

The bar chart shows the performance of a particular valve for which filed fallure data have been statjstically related to a low cycle/high stress condit ton, the conditioning hermetic conpressor.

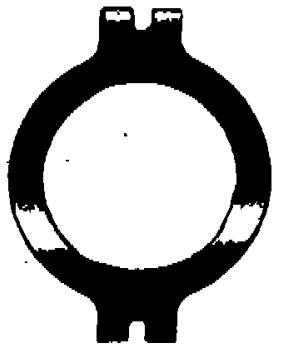

\section{AS STAMPED}

STRESS-LITE

STRPSS-LITE \& SHOTPE्EN

CYCLES

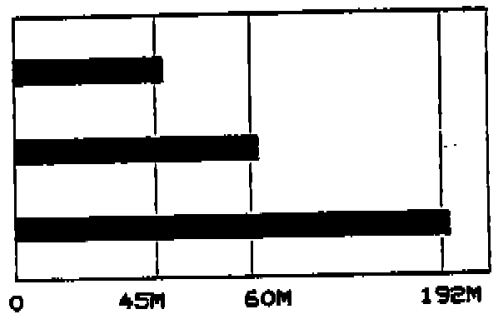

Edge Rounding Bending and torsional stresses are concentrated es (surface defects) but also at sharp outside cored edge, it would stili even if we had a theoretically perfect stil round the edges and distribbe necessary to use processes that wit a greater area. Here, again. the quali= wte the apolied stresses over a greater area. ty of the stamped edge is key: to the degresary. Too much edge finedge is smooth, less edge-rounding thickness of the reed on the sealishing can produce a taper in the thickness of the port. This may ing surface so that the reed will to prevent if large defects from be difficult or even impossible to prevent if avoid fatigue.

stamping must be removed in na

Depth and Magnitude of Compressive stresses

compressive stresses can be introduced by the of relatively low finishing process. They withy cases, are sufficient for the application, magnitude but, in many cased edges are near-perfect.

particularly if the stam as we have seen in the earlier sections of this paper, introduce much deeper residual compressive stresses and 
of a magnitude approaching the yield strength of the steet. It does so by indenting the surface so that the compressive stress is created in the subsurface layer that can be thought of as trying to push the indentation back out again. The magnitude of this compressive stress, then becomes a function of the yield strength of the material, as long as the surface is totally indented. As far as fatigue is concerned, the higher the magnitude of residual compression, the higher the fatigue strength and the longer the 1 ife of the reed. However, surface defects or discontinues always have a debiting effect on fatigue life, particularly if any are deeper than the layer of residual compressive stress (Fig. 6 ).

FIGURE 6. STRESS-LITE AND SHOT PEENING.

STRESS-LITE is a propritetary process developed to control edge radius, improve surface finish and to induce a high magnitude of residual compressive stress for inereased fatigue I ife. The il just ration is of a 2-cycle outboard engine reed Slanked out of stainiess steel, which has a drawing requirenent for a minimum of STRESS-L psi at the tips and 80, 000 osi compression on the balance of the reed. as 97,000 to 99,000 to process the ent 1 re reed to yillo residual stresses as high as 97,000 to 99,000 psi. Addition of shot Peening to the tips increases the sugh face residual compressive stress to as much as 132,000 psi.

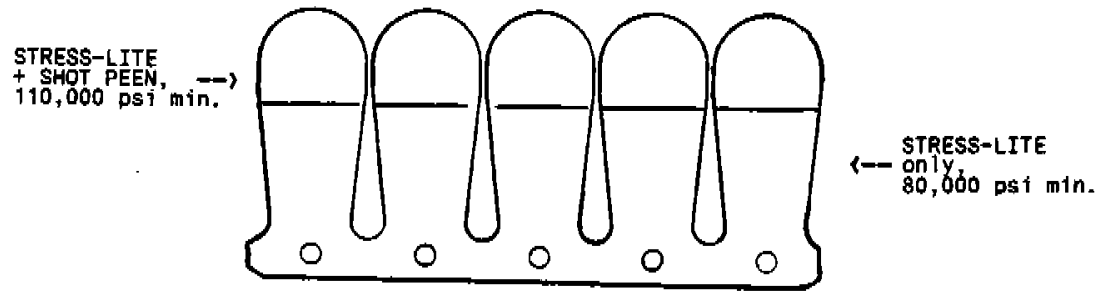

On a relatively thick part, say a quarter inch (6mm) or more, it is quite eesy to peen to a depth of 0.010 inch ( $0.25 \mathrm{~mm}$ ) to get below surface discontinues. Peening very thin valve reeds is an entirely different proposition and there are two interconnected concerns: distortion and internal stresses. Metal Improvement Company actua11y uses a controlled distortion (Peen Forming) to produce the aerodynamic curvatures on aircraft wing skins that can be as much as an inch ( $25 \mathrm{~mm}$ ) thick and 110 feet ( 34 meters) long (Ref. 9 ). Effectively Shot Peening reeds that may be on ly 0.06 inch $(0.4 \mathrm{~mm})$ thick while holding acceptable flatness tolerances, requires unusual technjques. Beyond the distortion, though, consideration must also be given to internal tensile stresses. Putting the surface into compression always produces a corresponding tensile stress in the core of the metal. If the depth of compression is too deep relative to the thickness, the core tensile stresses can become high enough to cause subsurface fatigue failures and shorten valve life (also see Fig. 1). Critical control of the depth. of compression can be exercised by intelligent use of the Aimen Intensity system (Ref. 10). Peenscan , a fluorescent tracer, is used to determine when 100x coverage has been reached (Ref. 11). These and other toots and techniques are applied today to gain great improvements and repeatability in the fatigue 1 ife of modern valve reeds.

\section{CONCLUSION}

Controlled Shot Peening is used very effectively in the manufacture of many components of both large and smal1 compressors. Very significant increases in 1 ife of valve reeds and rings can be achieved with shot Peening but it must be used in combination with advanced techniques for stamping and edge finishing, as we 1 as correct choice of material. 
Referençs necticut.

2. Fuchs, H. O., "Shot Peening stress Profiles", Metal Improvement Company, eloomfield, CT.

3. Koster, W. P., et. al., "Surface Integrity of Machined structural Components", Technical Report AFML-TR-70-11, March 1970.

4. Sandberg, E., Det Norske Veritas, Letter to Metal Improvement Company, September 1, 1983.

5. Lal, D. N., "The Use of Finite Element Method for Stress Analysis of Compressor Valves", Proceedings of the 1978 Purdue Compressor Technology Conference, Purdue University, West Lafayette, Indiana.

6. Heckert, R., Mogul, J., "The Application of Controlled shot Peening for the Prevention of Stress Corrosion Cracking", Metal Improvement company.

7. Dusi1, R, "On Blanking, Tumbling and Shot-Peening of Compressor valves", Proceedings of the 1978 Purdue compressor Technology Conference, Purdue University, West Lafayette, Indiana.

8. Carlyle Compressor Company, Syracuse, New York.

9. "Shot Peening Applications", Pg. 45, Metal Improvement Company, Bloomfield, CT.

10. "Shot Peening Applications", Pg. 61, Metal Improvement Company, Bloomfield, CT.

11. "Shot Peening Applications", Pg. 64, Metal Improvement Company, Bloomfield, CT.

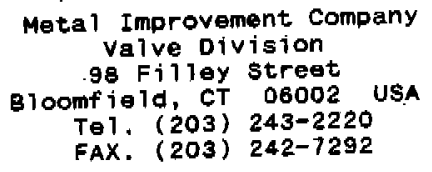

